\title{
INFORMACIÓN GENÉTICA, INTIMIDAD Y DISCRIMINACIÓN
}

\author{
Ana Victoria Sánchez Urrutia*
}

\begin{abstract}
Resumen: Las ventajas de la existencia de exámenes genéticos son muchas. Sin embargo, la información genética, mal utilizada, puede afectar la intimidad personal y familiar, generando, incluso, discriminación. En consecuencia, los datos derivados del genoma de una persona y de su familia son confidenciales y deben estar sujetos a medidas de seguridad adecuados, debiendo ser utilizados según los fines para los cuales fueron recabados y no deben ser cedidos a terceros, salvo consentimiento expreso del interesado o en virtud de mandamiento judicial. En términos similares se han pronunciado, por lo demás, la Declaración Universal sobre el Genoma Humano y los Derechos Humanos y el Consejo de Europa.
\end{abstract}

Palabras clave: Información genética, intimidad, discriminación, genoma humano, habeas data

\section{GENETIC INFORMATION, INTIMACY AND DISCRIMINATON}

\begin{abstract}
There are many advantages due to genetic tests. But genetic information, if badly applied, may affect personal and family intimacy or even arouse discrimination. Therefore, data derived from a person's and his family's genome are confidential; these should be subject to adequate measures of security, should be used only according to the purposes for which they were obtained and they should not be disclosed to third parties, except if the person involved gives his explicit consent or in virtue of a juridical mandate. Anyway, the Universal Declaration on the Human Genome and Human Rights and the European Council have given a similar opinion.
\end{abstract}

Key Words: Genetic informaton, privacy, discrimination, human genome, habeas data

\section{INFORMAÇAO GENÉTICA, INTIMIDADE E DISCRIMINAÇÃO}

Resumo: As vantagens decorrentes dos testes genéticos são muitas, porém, a informação genética utilizada de maneira inadequada pode comprometer a intimidade pessoal e familiar gerando discriminação. As informações do genoma de uma pessoa e de sua família são confidenciais e devem ser protegidas por medidas adequadas de segurança. Somente poderão ser utilizadas com fins específicos e não podem ser cedidas a terceiros, salvo quando de consentimento expresso do interessado ou em virtude de mandato judicial. Em termos semelhantes estão consagradas na Declaração Universal sobre o Genoma Humano e os Direitos Humanos e o Conselho da Europa.

Palavras chave: Informação genérica, intimidade, discriminação, genoma humano, hábeas data

\footnotetext{
Profesora de Derecho Constitucional y miembro del Observatori de Bioètica i Dret en la Universidad de Barcelona.

Correspondencia: asanchez@dret.ub.es
} 
Se plantean dudas sobre a quién pertenece la información derivada del ADN: ¿tiene un individuo, un grupo familiar o un colectivo derecho a controlar el uso de su información genética o es potestad exclusiva de los científicos?

La información que se deriva del $\mathrm{ADN}$ posee una potencialidad difícil de prever. Sólo a través del debate público, de la conciencia de los riesgos y los beneficios que se pudieran derivar de la información vital que revela el genoma, se pueden establecer las pautas por las cuales esa información redunde en beneficio de la persona y no se convierta en elemento de vulnerabilidad.

\section{LA PROTECCIÓN DEL ÁMBITO DE LO PRIVADO}

Las declaraciones de derechos, consecuencia de las revoluciones de finales del s. XVIII, pretenden proteger los ámbitos concretos en los que se desarrolla lo privado: el domicilio y las comunicaciones. El problema de la protección del espacio de lo privado, y la consecuente delimitación del dominio de lo íntimo, es formulado inicialmente a finales del s. XIX, como reacción al amarillismo periodístico que se genera a partir de la automatización de la imprenta. Desde esta perspectiva, el derecho a la intimidad sería el derecho que permite al individuo reservar frente a los demás información sobre sí mismo.

A partir de la segunda mitad del siglo XX, el debate sobre los límites a la intrusión en el ámbito de lo íntimo se vuelve más intenso. Los empresarios empiezan a seleccionar a los trabajadores sobre la base de nuevos criterios: test psicológicos, condición médica o estudios sociológicos. A la vez, el desarrollo de las tecnologías de la información aumenta exponencialmente la posibilidad del tratamiento masivo de datos, de su transmisión y uso.

Las Declaraciones internacionales de derechos se hacen eco de esta necesidad de protección del ámbito de lo privado. La Declaración Universal de Derechos Humanos establece que nadie será objeto de injerencias arbitrarias en su vida privada, su familia, su domicilio o su correspondencia..."(art. 12) y la Convención Americana sobre Derechos Humanos (San José, 1969) establece que "nadie puede ser objeto de injerencias arbitrarias o abusivas en su vida privada, en la de su familia, en su domicilio o en su correspondencia..." (Art. 11.2).

A su vez, el desarrollo tecnológico ha supuesto nuevas formas e intensidades de invasión de lo privado. El perfeccionamiento de los dispositivos electrónicos de vídeo vigilancia y escucha han posibilitado nuevas formas de vulnerar el domicilio, las comunicaciones personales y el derecho a la propia imagen. La evolución de las tecnologías de tratamiento y almacenamiento de la información han supuesto nuevas vías de intromisión en el ámbito de la privacidad que han desembocado en la necesidad de articular nuevos mecanismos que prevean un razonable control de la información personal. El desarrollo de las biotecnologías y, en especial, las nuevas tecnologías genéticas, han supuesto, además, la necesidad de replantear los límites de intromisión en la esfera de lo privado $\mathrm{y}$, a la vez, han generado nuevos dilemas que complican la comprensión de lo privado, los espacios de su protección y los criterios de ponderación frente a otros derechos o bienes tutelados por la constituciones estatales y declaraciones internacionales.

Las revoluciones liberales supusieron la introducción de garantías formales de protección del ámbito de lo privado. El derecho a la inviolabilidad del domicilio fue reconocido en el Bill of Rights de Virginia (1776) ${ }^{1}$ como

\footnotetext{
"That general warrants, whereby an officer or messenger may be commanded to search suspected places without evidence of a fact committed, or to seize any person or persons not named, or whose offense is not particularly described and supported by evidence, are grievous and oppressive and ought not to be granted" The Virginia Declaration of Rights: Sección 10, aprobada el 12 de junio de 1776.
} 
reacción contra las prácticas abusivas de las autoridades coloniales inglesas, que expedían mandamientos generalizados para el registro domiciliario de los habitantes de las colonias americanas. Unos años más tarde, en la cuarta enmienda de la Constitución de los Estados Unidos, se instauraron garantías frente a los registros arbitrarios(1). Por su parte, la Asamblea Nacional francesa proclamó en 1790 la inviolabilidad de la correspondencia y, un año más tarde, se suprimieron los controles institucionales(2).

El derecho a la intimidad supone la existencia de una esfera de protección frente a los demás, como de un derecho abstracto a mantener reservado el ámbito más próximo de la vida privada y familiar que se formula como reacción al perfeccionamiento de las tecnologías de la información. A finales del siglo XIX, la mecanización de la imprenta y la consecuente capacidad de difundir rápidamente la información a gran cantidad de público, llevó a dos juristas estadounidenses, Warren y Brandeis, a describir la necesidad de la protección del ámbito de lo privado y exigir la capacidad de reaccionar ante el daño emocional que la invasión de este ámbito vedado suponía(3). Definieron el derecho a la intimidad como el derecho de las personas a "no ser molestadas" (the right to be alone). Los derechos que, tradicionalmente, servían como límite a la libertad de imprenta, el derecho al honor, en cuanto capacidad de reacción frente al menoscabo de la reputación, y el derecho a la propiedad intelectual, en cuanto derecho de las personas a que sus creaciones literarias y científicas no sean difundidas sin su consentimiento, no eran suficientes para garantizar la protección frente a la invasión del ámbito de lo privado.

Warren y Brandeis llegaron a la conclusión de que la posibilidad de reaccionar frente a la vulneración del ámbito de lo privado debe darse en el contexto de las siguientes premisas:
El derecho a la intimidad (privacy) no prohíbe la publicidad de hechos que sean de interés público o interés general.

No se vulnera el derecho a la intimidad si lo difundido es en cumplimiento de la ley.

- No hay vulneración de la intimidad cuando lo privado se publica con consentimiento.

- La verdad del hecho divulgado no exime de responsabilidad por su divulgación.

- La ausencia de ánimo de causar daño no exime de responsabilidad.

El derecho a la intimidad supone que no se revelen ni se difundan datos o hechos de la vida privada, el reconocimiento de la intimidad corporal, que se reconozca un espacio de autonomía personal donde los demás no puedan entrar, y la autodeterminación informativa. En este contexto, hay que entender el derecho a la intimidad no sólo como un derecho que debe ser protegido frente a invasiones, sino como una esfera de autonomía y de autodefinición personal.

Se vulnera el derecho a la intimidad por la revelación o divulgación de hechos o datos de la vida privada de una persona o de una familia.

En Estados Unidos el derecho a la intimidad, en cuanto derecho a la autonomía personal, ha sido desarrollado a partir de la interpretación de la cláusula del debido proceso legal (due process of law) de la XIV enmienda de la Constitución. Según este enunciado, ninguna persona podrá ser privada de su vida, libertad y propiedad sin un debido proceso legal. El Tribunal Supremo de los Estados Unidos ha considerado la libertad, en el contexto del derecho a un debido proceso, como un derecho subjetivo a la intimidad (privacy) que se configura como la autonomía en la toma de decisiones en la esfera de la vida privada. Así, estableció que de este derecho a la vida privada 
se puede derivar el derecho de las parejas a decidir sobre la anticoncepción ${ }^{2}$ o el derecho de la mujer a decidir sobre la terminación voluntaria del embarazo ${ }^{3}$.

El Tribunal Europeo de Derechos Humanos ha entendido que el derecho a la vida privada protegido por el artículo 8 del $\mathrm{CEDH}$, supone desarrollo de la vida privada sin que haya injerencia de los poderes públicos. Sólo puede haber injerencia por razones justificadas. La penalización de las conductas privadas, como las relaciones homosexuales, no están justificadas ${ }^{4}$.

Tanto el desarrollo de las tecnologías de la información, como la posibilidad del almacenamiento, tratamiento y manipulación masiva de datos a través de la informática, y la probabilidad casi ilimitada de difusión de datos a través de las redes, han supuesto una gran revolución en las posibilidades de tratamiento de la información personal, con los consecuentes riesgos para la privacidad. En relativamente poco tiempo, se ha pasado de los sótanos llenos de archivos polvorientos a la capacidad de almacenaje electrónico y la difusión en red de grandes cantidades de información.

Frente a la posibilidad de un tratamiento masivo de datos derivado del desarrollo de las nuevas tecnologías, se ha formulado el derecho a la autodeterminación informativa, en cuanto del derecho a la intimidad se deriva una garantía positiva en forma de control de los datos relativos a la propia persona (habeas data). Se habla, entonces, de una garantía frente a las potenciales agresiones a los derechos fundamentales de la persona, que implica el derecho del individuo a controlar dónde están

\footnotetext{
2 Griswold vs. Connecticut, 381 U.S. 479 (1965).

Roe vs. Wade, 410 U.S. (1973).

4 STEDH de 31 de julio de 2000. Caso A. D. T. contra Reino Unido.
}

y en qué forma son utilizados sus datos personales. La autodeterminación no es un elemento distinto a la intimidad, sino un elemento de control que abre la posibilidad de decidir sobre el uso de los datos personales, un aspecto crucial del derecho a la intimidad(4). Esta necesidad de garantizar el derecho de los ciudadanos a controlar sus datos personales se ha visto reflejada en varias constituciones latinoamericanas. Por ejemplo, la Constitución Brasileña de 1998 constitucionaliza el derecho al habeas data (art. 5) y la reforma de la Constitución Argentina operada en 1994 lo garantiza en su art. 43(5).

\section{LA INFORMACIÓN GENÉTICA}

Los cromosomas son cuerpos en forma de filamento portadores de los genes que se encuentran en el núcleo de las células y son considerados los portadores de la información biológica. Cada célula del cuerpo humano tiene 23 pares de cromosomas, excepto las reproductoras (óvulos o espermatozoides) que contienen la mitad. Los cromosomas están formados por $\mathrm{ADN}$, que es el material genético de los órganos vivos descrito por primera vez por Watson y Crack(6) como una estructura formada por dos cadenas de nucleótidos trenzadas en una doble hélice. Dentro del genoma se pueden distinguir dos tipos de ADN: el codificante y el no codificante. El codificante, formado por frecuencias en las cuales hay pocas variaciones entre individuos, está constituido por fragmentos del ADN que determinan a los diferentes genes que definirán las características de las personas a través de la síntesis proteica. Al ADN no codificante no se le relaciona con la síntesis de proteínas, no se ha descubierto su función biológica, esto es, aunque forma parte de la estructura interna del ADN, no se traduce $\mathrm{y}$, por tanto, no aporta información al producto final, la proteína. La suma de estas secuencias no codificantes representan más del $90 \%$ de la longitud del genoma humano(7) y se caracteriza por la gran variabilidad de sus características 
de un individuo a otro. Esta variabilidad de sus secuencias lo hace extremadamente apto desde la perspectiva de la medicina legal a efectos de identificación de las personas(8).

Un fragmento de ADN es cuanto se precisa para que un individuo sea distinto a otro. El estado de salud de una persona está determinado por una suerte de lotería genética puesta en marcha por la herencia(9). Los genes determinan las características de cada persona. Para saber cómo trabajan, primero hay que identificar las proteínas que producen $y$, posteriormente, ver qué función realizan.

\section{A. ¿Cómo se obtiene la información derivada del ADN?}

La información derivada del ADN puede extraerse en el contexto del tratamiento sanitario, en estudios poblacionales y en pruebas de identificación.

Las pruebas genéticas con fines de atención sanitaria se refieren a pruebas que sirvan para:

- Diagnosticar y clasificar una enfermedad genética;

- Identificar portadores no afectados de un gen defectuoso para asesorarles sobre el riesgo de tener hijos afectados;

- Detectar una enfermedad genética grave antes de la manifestación clínica de los síntomas con el fin de mejorar la calidad de vida utilizando medidas secundarias preventivas y/o evitando dar a luz la descendencia afectada;

- Identificar personas con riesgo de contraer la enfermedad cuando un gen defectuoso y un determinado estilo de vida sean importantes como causa de la enfermedad.

La prueba genética puede ser un elemento de diagnóstico una vez que los síntomas de la enfermedad han aparecido. La identificación de portadores se realiza cuando se sospecha que la persona sometida a la prueba puede transmitir un gen, responsable de una enfermedad genética recesiva, a sus descendientes. La utilidad de esta prueba es asesorar a la persona portadora en sus decisiones reproductivas.

Las pruebas sobre el riesgo de contraer enfermedades de origen genético son denominadas también de predisposición genética. Una cantidad apreciable de enfermedades están originadas por un componente genético que, junto al ambiente, pueden originar la enfermedad. Las pruebas de predisposición pueden variar según un abanico que abarca desde casi la certeza hasta una cierta predisposición a padecer enfermedades comunes(10).

El diagnóstico genético se refiere a las pruebas realizadas para diagnosticar una presunta dolencia en una persona o en varios miembros de una familia en el marco de un estudio familiar. En este contexto, es una serie de pruebas a la que se someten los miembros de una familia para estudiar la incidencia de una determinada enfermedad genética dentro del grupo estudiado.

El cribado genético se refiere a pruebas genéticas realizadas en el conjunto de la población o en el subconjunto de la misma, sin previa sospecha de que las personas sean portadoras del rasgo. El cribado genético puede ser producto de una determinada política pública de prevención como lo son, por ejemplo, las pruebas de diagnóstico prenatal. También puede suponer la necesidad de vigilancia de la salud en ciertos contextos determinados.

Las pruebas de identificación sobre el ADN no codificante son aplicadas tanto en la investigación básica (estudios poblacionales) como en la aplicada. El uso aplicado puede darse en las siguientes circunstancias(11): 
- Diagnóstico de paternidad biológica y otros tipos de parentesco.

- Identificación de sospechosos por comparación de vestigios biológicos en procedimientos penales.

- Identificación de individuos post-mortem.

El análisis de ADN se realiza a partir de una extracción de sangre, o simplemente saliva, que se practica a la madre, al hijo o al presunto padre. Para establecer la paternidad biológica se comparan las características genéticas resultantes de los análisis de ADN de la madre y del hijo con los del presunto padre. En primer lugar se comparan el hijo y la madre, así se conoce la mitad del material genético que el hijo ha heredado de su madre, deduciendo de ésta cuál es la otra mitad que ha tenido que heredar de su padre biológico. Además, los avances más recientes permiten hacer análisis de este tipo sin necesidad de analizar el material genético de la madre.

Para la investigación relacionada con los delitos se examina lo que se denomina la huella genética, es decir, el material genético exclusivo de cada individuo. Como el ADN de un individuo es el mismo, independientemente de si son estudiados los cabellos, células blancas de la sangre, etc., cualquier muestra biológica sirve para analizar la huella genética. La identificación biológica de los individuos se realiza comparando la huella genética de cada sospechoso con la huella genética obtenida tras el análisis del vestigio biológico de la prueba(11, p.118).

La identificación de los individuos postmortem se puede hacer identificando las muestras biológicas del cuerpo analizado con muestras provenientes de algún banco de datos biológicos en los cuales haya muestras del sujeto o, si no es posible, comparando sus muestras biológicas con las de un familiar.

\section{B. Las Precauciones}

Por más pequeños que sean los rastros que se dejan al pasar, éstos pueden servir para la identificación de la huella genética que excluye a un individuo de todas las demás personas. La información genética, además, puede descifrar las relaciones de la familia biológica, el que se padezca una determinada enfermedad o que se tenga la posibilidad de padecerla. Los bancos de tejidos, como lo son, por ejemplo, los bancos de sangre, almacenan una información que, potencialmente, revela ilimitada información sobre el individuo(12).

La información que se deriva del ADN no sólo es altamente sensitiva sino que tiene una potencialidad desconocida: la de revelar información ilimitada sobre el individuo, datos de cuya existencia no se tiene conciencia, información que aún está por descifrarse.

Las ventajas de la existencia de exámenes genéticos son muchas. Sin embargo, la información genética mal utilizada, que permite etiquetar a los individuos, puede generar discriminación en cuanto al trato diferente no justificado.

La información genética de una persona puede afectar la intimidad personal y familiar, pues el resultado del diagnóstico genético es relevante para su familia biológica. Este diagnóstico "tiene no sólo efectos sobre el paciente (propositus) sino que todos los individuos emparentados con éste se ven afectados"(13). Algunos genetistas argumentan, por ejemplo, que debe considerarse como sujeto de diagnóstico a toda la familia antes que al individuo individualmente considerado $(10, p$. 69). Por ello, cuando se hace referencia al derecho a la intimidad en relación con los datos médicos y, en especial, al genoma y a la información que, en general, puede derivarse del ADN, dicho derecho, en la mayoría de los casos, se relaciona con la protección de la intimidad familiar. 
Cuando se hace referencia a la intimidad genética, normalmente se relaciona con la confidencialidad, el secreto o el respeto a la privacidad de la información(14). Sin embargo, el desarrollo de las circunstancias y la posibilidad de las pruebas genéticas hacen que la intimidad genética sea invocada en relación con el derecho a controlar los datos personales, esto es, su generación, el derecho a determinar la información genética que se puede tener de una persona o la que ella quiere saber y el derecho de terceros, afectados por una prueba genética individual, a saber los resultados. Por otra parte, se cuestiona la legitimidad de los poderes públicos o particulares a almacenar información genética.

La necesidad de hacer pruebas genéticas en ciertos contextos puede estar justificada por motivos de interés o relevancia pública. Sin embargo, esta relevancia no justifica que el resultado de ciertas pruebas sea hecho público. En este sentido, se debe estar siempre consciente de que los datos derivados del genoma de una persona y de su familia son confidenciales y deben guardarse con medidas de seguridad adecuadas, deben utilizarse sólo con los fines para los cuales fueron recabados $\mathrm{y}$ no deben ser cedidos a terceros, salvo consentimiento expreso del interesado o por motivo de mandamiento judicial.

\section{La Declaración Universal sobre el Genoma} y los Derechos Humanos establece que una investigación, un tratamiento o un diagnóstico en relación con el genoma de un individuo sólo podrán efectuarse previa evaluación rigurosa de los riesgos y las ventajas que entraña y de conformidad con la legislación nacional. En todo caso -establece la declaración- se recabará consentimiento previo, libre e informado de la persona interesada.

En este sentido, el Consejo de Europa recomienda que cualquier procedimiento de realización de pruebas genéticas y de cribado debe ir acompañado por el oportuno asesoramiento, tanto antes como después de los procedimientos. El asesoramiento debe ser de carácter no directivo: la información debe incluir los hechos médicos pertinentes, los resultados de las pruebas, así como las consecuencias y opciones. Se debe explicar el objeto y naturaleza de las pruebas y señalar los posibles riesgos. La información debe ser adaptada a las circunstancias en que las personas y las familias reciban la información genética. Cuando sea necesario, debe hacerse todo lo posible por mantener el apoyo a las personas que hayan sido objeto de las pruebas ${ }^{5}$. En el contexto del derecho a la intimidad genética se ha alegado el derecho a no saber. La Declaración Universal sobre el Genoma y Derechos Humanos establece que debe respetarse el derecho de toda persona a decidir ser informado o no de los resultados del examen genético o de sus consecuencias.

Todas estas cautelas relacionadas a cómo se trasmite la información derivada de una prueba genética o de ADN están justificadas por lo relevante de la información. Muchas enfermedades que pueden diagnosticarse por pruebas genéticas no tienen tratamiento terapéutico y pueden diagnosticarse, además, años antes de que la persona presente los primeros síntomas.
Recomendación 3 (1992) sobre pruebas genéticas y de cribado con fines sanitarios. 


\section{Referencias:}

1. Sykes ChJ. The end of Privacy. Personal Rights in the Surveillance Society. New York: St. Martin Press; 1999: 83-84.

2. Martín Morales R. El régimen constitucional del secreto de las comunicaciones. Madrid: Civitas; 1995: 22.

3. Warren SD, Brandeis LD. The Right to Privacy. Harvard Law Review Vol. IV December 15, 1890; 5: 193-220.

4. Rodríguez Ruiz B. El secreto de las comunicaciones: tecnología e intimidad. Madrid: Mc Graw-Hill; 1998: 15.

5. Guadamuz A. Habeas Data vs. the European Data Protection Directive. The Journal of Information, Law and Technology (JILT) 2001(3) [Sitio en Internet] Disponible en http://elj.warwick.ac.uk/jilt/002/guadamuz.html Acceso en octubre de 2002.

6. Watson JD, Crick FHC. Molecular Structure of Nucleic Acids. Nature; 4356: 737-738.

7. González-Duarte R. Aislamiento y caracterización de genes humanos. Aplicaciones terapéuticas. En: Casado M, González R, eds. Los retos de la genética del siglo XXI: genética y bioética. Barcelona: Edicions Universitat de Barcelona; 1999: 26.

8. Etxeberría Gurudi JF. Los análisis de ADN y su aplicación en el proceso penal. Granada: Editorial Comares; 2000: 12.

9. Grace ES. La biotecnología al desnudo. Promesas y realidades. Barcelona: Anagrama; 1998: 87.

10. British Medical Association. Human Genetics. Choice and Responsibilities. Oxford: Oxford University Press; 1998: 95.

11. Pancorbo M, Castro A, Fernández-Fernández I. El valor de la huella genética como prueba biológica. En: Casado M, González R, eds. Los retos de la genética del siglo XXI: genética y bioética. Barcelona: Edicions Universitat de Barcelona; 1999: 115-166.

12. Murray TH. Genetic Exceptionalism and 'Future Diaries': Is Genetic Information Different from other Medical Informatics? En: Rothstein M, ed. Genetic Secrets: Protecting Privacy and Confidentiality in Genetic Era. New Haven: Yale University Press; 1997: 63.

13. Fibla J. Estrategias en el diagnóstico molecular de las enfermedades hereditarias. En Casado M, González $\mathrm{R}$, eds. Los retos de la genética del siglo XXI: genética y bioética. Barcelona: Edicions Universitat de Barcelona; 1999: 39.

14. Allen A. Genetic Privacy: Emerging Concepts and Values. En: Rothstein M, ed. Genetic Secrets: Protecting Privacy and Confidentiality in Genetic Era. New Haven: Yale University Press; 1997: 60. 